\title{
GMR
}

\section{Molecular cloning and characterization of a subtilisin-like protease from Arabidopsis thaliana}

\author{
D.H. Li, H. Xi, X.B. Yu and Y.P. Cai \\ College of Life Sciences, Anhui Agricultural University, Hefei, China \\ Corresponding author: Y.P. Cai \\ E-mail: yongpcai@163.com \\ Genet. Mol. Res. 14 (4): 16535-16545 (2015) \\ Received June 18, 2015 \\ Accepted September 2, 2015 \\ Published December 9, 2015 \\ DOI http://dx.doi.org/10.4238/2015.December.9.25
}

ABSTRACT. The Arabidopsis thaliana genome encodes 56 subtilisin-like serine proteases (subtilases). In order to evaluate the protease activity of a previously uncharacterized subtilase, designated as AtSBT1.9, we cloned its full-length cDNA from $A$. thaliana seedlings. An AtSBT1.9 mature peptide coding sequence was inserted into the bacterial expression vector, pMAL$\mathrm{c} 2 \mathrm{x}$, and the recombinant vector was transformed into Escherichia coli BL21 (DE3). The recombinant AtSBT1.9 tagged by maltose binding protein (MBP) was induced as a $117.5-\mathrm{kDa}$ protein in the soluble form in $E$. coli BL21 (DE3). MBP-AtSBT1.9 was expressed at a level of $11 \%(w / w)$ of the bacterial total protein. Protein purification using Amylose Resin revealed a recombinant AtSBT1.9 protease activity of $9.23 \mathrm{U} / \mathrm{mg}$ protein at $\mathrm{pH} 7$ and $25^{\circ} \mathrm{C}$. Maximal activity occurred over a broad $\mathrm{pH}(7-8)$ and temperature $\left(25^{\circ}-42^{\circ} \mathrm{C}\right)$ optimal range. Validation of AtSBT1.9 protease activity would help in characterizing its in vivo function in $A$. thaliana.

Key words: Arabidopsis thaliana; Bacterial expression; Protease activity; Serine protease; Subtilase 


\section{INTRODUCTION}

Subtilisin-like proteases (subtilases) are a type of serine proteases and constitute the largest group of peptidases (Dodson and Wlodawer, 1998; Figueiredo et al., 2014). Eukaryotic subtilases are encoded by a variety of organisms, including animals, plants, and fungi, and form the SB subfamily within the S8 serine protease family (Rautengarten et al., 2005).

Several subtilases have been identified in plants. For example, 63, 56, and 15 subtilase genes are known in Oryza sativa, Arabidopsis thaliana, and Lycopersicon esculentum, respectively (Meichtry et al., 1999; Rautengarten et al., 2005; Tripathi and Sowdhamini, 2006; Figueiredo et al., 2014). Therefore, it is likely that subtilases contribute significantly to the developmental processes and signaling cascades in plants (Rautengarten et al., 2005). An A. thaliana subtilase, AtSBT3.3, seems to be involved in activating downstream immune signaling during plant-pathogen interactions (Ramírez et al., 2013). The loss-of-function gene mutations SDD1 (AtSBT1.2) and ALE1 (AtSBT2.4) lead to abnormal stomatal density and leaf shape, respectively. These results indicate that some subtilases may play a role in developmental processes through the generation of peptide signals (von Groll et al., 2002; Matos et al., 2008). Overexpression of another subtilase (AtSBT5.4) produces a clavata-like phenotype with fasciated inflorescence stems and compounded terminal buds. Appearance of this phenotype depends on AtSBT5.4 activity, because substitution of the active-site serine abolished the overexpression phenotype (Liu et al., 2009). Other specific functions performed by plant subtilases include root development (Sénéchal et al., 2014) and seed germination (Rautengarten et al., 2008). Although several subtilases have been characterized, most of their functions in plants remain unknown.

AtSBT1.9 (GenBank accession No. NP_569044) is an A. thaliana subtilase ubiquitously expressed in leaves, roots, stems, flowers, inflorescences, and seedlings (Rautengarten et al., 2005). However, the natural AtSBT1.9 protein hasnever been purified from $A$. thaliana, and no reports to date describe its function or provide its biochemical characterization. We expressed the AtSBT1.9 protein in E. coli by cloning its cDNA and constructing a bacterial expression system. This provided a convenient and abundant source of recombinant AtSBT1.9 protein, which allowed for an in vitro protease activity assay and enzyme characterization. Recombinant AtSBT1.9 will enable further functional studies to establish its putative role in $A$. thaliana.

\section{MATERIAL AND METHODS}

\section{Plant material, bacterial strains, andvectors}

Arabidopsis thaliana plants (ecotypes Col-0) were used to clone cDNA of AtSBT1.9. Sterilized seeds were plated on $1 / 2 \mathrm{MS}$ solid medium and kept at $4^{\circ} \mathrm{C}$ for three days, and then transferred to growth chambers at $22^{\circ} \mathrm{C}$ under $16 \mathrm{~h}$ light $/ 8 \mathrm{~h}$ dark regime. E. coli $\mathrm{DH} 5 \mathrm{\alpha}$ and vector pMD18-T (TaKaRa, Japan) were used for DNA manipulation. E. coli BL21 (DE3) and vector pMALc2x (New England Biolabs, USA) were used for expression of AtSBT1.9 gene.

\section{Cloning of AtSBT1.9 cDNA}

Total RNA was isolated from 10-day-old $A$. thaliana seedlings using an RNeasy Mini Kit (Qiagen, USA). We designed a specific sense primer, ForP1, containing a BamHI site (5'-CGA 
GGA TCC ATG GGG ATG ACC GTC GTA-3', and a specific antisense primer, RevP2, containing a Sall site (5'-GC GTC GAC TCAAGA CTC TTG GAC AAG GC-3'), based on the mRNA sequence of AtSBT1.9 (GenBank accession No. NM_126109). Following RNA extraction, reverse transcriptase polymerase chain reaction (RT-PCR) was performed using the protocol of RNA LA PCRkit (TaKaRa, Japan). Primer RevP2 was used to reverse transcribe the double-stranded cDNA in a $25-\mu \mathrm{L}$ reaction mixture containing $10 \mu \mathrm{g}$ total RNA, and the mixture was incubated at $42^{\circ} \mathrm{C}$ for 60 $\mathrm{min}$. The reaction was terminated by heating to $70^{\circ} \mathrm{C}$ for $5 \mathrm{~min}$ and chilling on ice for $5 \mathrm{~min}$. Primer ForP1 and RevP2 pairs were used for PCR amplification with $1 \mu \mathrm{L}$ of the double-stranded cDNA reaction mixture as the template. Our PCR program was as follows: pre-denaturation for 4 min at $94^{\circ} \mathrm{C}$, then 30 cycles of $30 \mathrm{~s}$ at $94^{\circ} \mathrm{C}, 45 \mathrm{~s}$ at $62^{\circ} \mathrm{C}, 2 \mathrm{~min}$ at $72^{\circ} \mathrm{C}$, and finally $10 \mathrm{~min}$ at $72^{\circ} \mathrm{C}$. The PCR system without the total RNA template was used as a negative control. PCR products were subjected to agar electrophoresis, and the appropriate band removed and purified with a DNA Fragment Recovery Kit (TaKaRa, Japan). The purified fragment was then cloned into a pMD18-T vector and confirmed by DNA sequencing.

\section{Construction of the vector pMAL-AtSBT1.9}

The presence of a signal peptide was determined with the SignalP 4.1 server (www.cbs. dtu.dk/services/SignalP/). To obtain clones that only contain the mature peptide-coding region of AtSBT1.9, another primer (ForMP1), also containing a BamHI site (5'-CGA GGA TCC GAG ACC TCT CCT TAC ATC ATC-3'), was designed, based on the mature peptide coding sequence of the target clone. PCR (with ForMP1 and RevP2 as primer pairs) was then performed following the same PCR program as before. The amplified product of this second round of PCR was cloned into pMD18-T and sequenced. The recombinant vector pMD18-T-AtSBT1.9 was digested with BamHI and Sall, and the resultant AtSBT1.9 fragment was cloned into the BamHI and Sall sites of the expression vector pMAL-c2x, and designated as PMAL-AtSBT1.9. The vector pMAL-AtSBT1.9 was introduced into E. coli BL21 (DE3) cells by electroporation. The empty vector was also introduced into BL21 (DE3) as a negative control.

\section{Fusion protein production in E. coli}

E. coli BL21 (DE3) cells containing the plasmid of interest were grown at $37^{\circ} \mathrm{C}$ for $12 \mathrm{~h}$ in $5 \mathrm{~mL}$ LB medium containing appropriate antibiotics (100 $\mu \mathrm{g}$ ampicillin/mL). The culture was diluted 1:100 $(\mathrm{v} / \mathrm{v})$ to $300 \mathrm{~mL}$ of the same medium, followed by incubation at $37^{\circ} \mathrm{C}$. When the $\mathrm{OD}_{600}$ value reached 0.5 , isopropyl $\beta$-D-thiogalactopyranoside (IPTG) was added to each culture to a final concentration of $0.2 \mathrm{mM}$. Then, cells were grown at $18^{\circ} \mathrm{C}$ for $12 \mathrm{~h}$ or at $37^{\circ} \mathrm{C}$ for $5 \mathrm{~h}$ to induce expression.

\section{Purification of fusion protein}

Recombinant bacteria induced by IPTG were harvested by centrifugation and resuspended in column buffer $(20 \mathrm{mM}$ Tris- $\mathrm{HCl}, \mathrm{pH} 7.4,200 \mathrm{mM} \mathrm{NaCl}, 1 \mathrm{mM}$ EDTA, and $10 \mathrm{mM}$ $\beta$-mercaptoethanol). This suspension was sonicated at $4^{\circ} \mathrm{C}$ to yield the cell lysate, which was then centrifuged at 20,000 $\mathrm{g}$ for $20 \mathrm{~min}$. The pellet was removed and the supernatant used for purification. The fusion protein was purified using amylose resin (New England Biolabs, USA) which is an affinity matrix for isolation of proteins fused to maltose-binding protein (MBP). Our 
purification protocol was as follows: 1) In a 15-mL conical tube, $2 \mathrm{~mL} 50 \%(\mathrm{v} / \mathrm{v})$ amylose slurry was added and washed three times with cold column buffer, keeping the tubes at $4^{\circ} \mathrm{C}$ until the samples were ready; 2) The crude extract collected $(6 \mathrm{~mL})$ was transferred to the pretreated amylose resin. The system was rocked gently at $4^{\circ} \mathrm{C}$ for $3 \mathrm{~h}$ to allow binding; 3) Unbound material was removed by centrifugation at $4500 \mathrm{~g}$ for $5 \mathrm{~min}$, at $4^{\circ} \mathrm{C}$; 4) The resin was washed three times with cold column buffer; 5) The resin was transferred to a gravity flow column (Sigma-Aldrich, USA); and 6) the protein was eluted with column buffer plus $10 \mathrm{mM}$ maltose. The bound proteins were fractionally eluted outin $250 \mu \mathrm{L}$ fractions. Quality of the eluted fractions was assessed using sodium dodecyl sulphate poly agarose gel electrophoresis (SDS-PAGE). The fractions containing MBP-AtSBT1.9 were pooled and dialysed against $100 \mathrm{mM}$ Tris- $\mathrm{HCl}$ buffer, $\mathrm{pH} 7$, and stored at $-80^{\circ} \mathrm{C}$ until used for the activity assay. SDS-PAGE was performed ona $12 \%(\mathrm{v} / \mathrm{v}) \mathrm{gel}$, which was then stained with Coomassie brilliant blue. Protein concentration was determined by the Bradford method.

\section{Protease activity assay}

Protease activity was assessed according to the methods described previously (Cheng et al., 2009) with slight modifications. Briefly, azocasein (Sigma-Aldrich, USA) was used as a substrate for the purified MBP-AtSBT1.9 protein. It was dissolved in $100 \mathrm{mM}$ Tris-HCl buffer, $\mathrm{pH} 7$, to a final concentration of $0.5 \%(\mathrm{w} / \mathrm{v})$. The azocasein solution was then mixed with $4 \mu \mathrm{g} /$ $\mathrm{mL}$ of the MBP-AtSBT1.9 protein in a $500-\mu \mathrm{L}$ reaction system. This mixture was incubated at $25^{\circ} \mathrm{C}$ for $2 \mathrm{~h}$. Finally, $500 \mu \mathrm{L} 40 \%$ (w/v) trichloroacetic acid (TCA) was added to the mixture to terminate the reaction. After letting the mixture stand at room temperature for $15 \mathrm{~min}$, the liquid fraction resulting from centrifugation at $13,000 \mathrm{~g}$ for $10 \mathrm{~min}$ was collected, and its absorbency at $335 \mathrm{~nm}$ noted. One unit $(U)$ of activity was defined as the amount of enzyme required to increase the absorbency by 0.01 unit per minute. To determine optimal $\mathrm{pH}$ and temperature conditions, reactions were carried out in buffers having various $\mathrm{pH}$ values $(2-12)$ at $25^{\circ} \mathrm{C}$ or by incubation at various temperatures $\left(18^{\circ}-70^{\circ} \mathrm{C}\right)$ in buffers, $\mathrm{pH}$, under the conditions described above, respectively. The reaction blank used was $40 \%$ TCA. To test effects of MBP tag and AtSBT1.9 signal peptide on protease activity, the fusion protein consisting of MBP tag and fulllength AtSBT1.9 (with its signal peptide included) was produced and purified as in the abovementioned procedures. Cleavage of MBP tags was carried out by Factor Xa Protease using $\mathrm{pMAL}^{\mathrm{TM}}$ Protein Fusion and Purification System (New England Biolabs, USA). Protease activities of the expressed AtSBT1.9 proteins with different fusion forms (with or without MBP and signal peptide) were tested using standard protocols.

\section{Western blotting}

The MBP-AtSBT1.9 fusion protein was expressed in E.coli using the conditions described above. Total bacterial protein was prepared and fractionated on $12 \%(\mathrm{v} / \mathrm{v})$ SDS-PAGE and transferred to nitrocellulose membranes. Immunodetection was performed using an anti-MBP antibody produced in mice (Sigma-Aldrich, USA) against MBP-AtSBT1.9 at a 1:5,000 dilution (v/v) as the primary antibody, and using alkaline phosphatase-conjugated anti-mouse immunoglobulins (1:10,000 dilution, v/v) as the secondary antibody (Sigma-Aldrich). Signals were visualized by employing NBT (nitroblue tetrazolium chloride)/BCIP (5-bromo-4-chloro-3'-indolyl phosphate p-toluidine salt) in the phosphatase reaction. 


\section{RESULTS}

\section{Cloning of AtSBT1.9 gene}

The cloned AtSBT1.9 cDNA had a length of $2211 \mathrm{bp}$. Sequencing results confirm that the cDNA is consistent with the open reading frame of AtSBT1.9 gene sequence deposited in the NCBI database with GenBank accession No. NM_126109. The AtSBT1.9 cDNA encodes a deduced protein of 736 amino acids containing a signal peptide of 20 amino acids at the N-terminus domain, based on prediction of signal peptide with the Signal P 4.1 server (Figure 1). Therefore, another set of PCR was carried out with primer pairs that flanked the sequence of AtSBT1.9 mature peptide, resulting in a 2151-bp fragment (Figure 2). Accordingly, AtSBT1.9 mature peptide of 716 amino acids was deduced to possess a calculated molecular mass of $77.5 \mathrm{kDa}$.

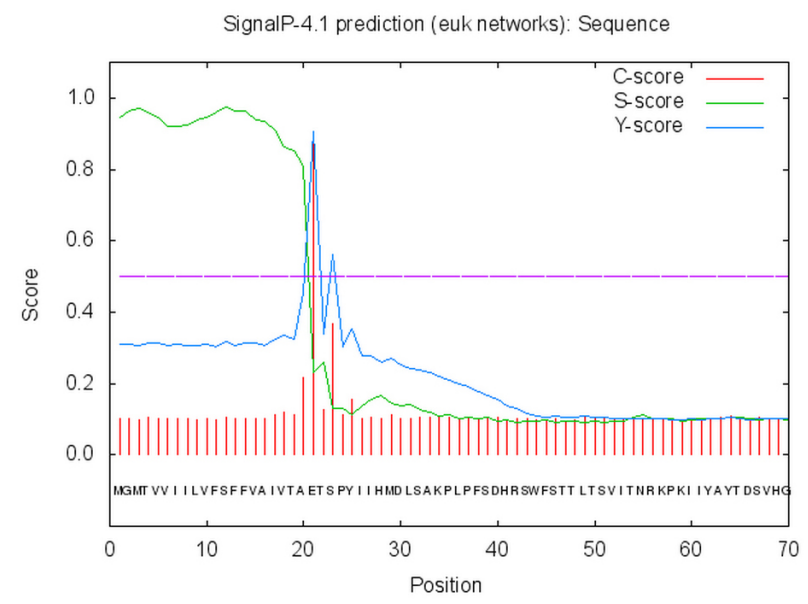

Figure 1. Presence of a signal peptide was determined with the SignalP 4.1 server. The AtSBT1.9 protein has a predicted signal peptide with a cleavage sequence at amino acid 20-21 from its $\mathrm{N}$-terminus. C score for original cleavage site, S score for the signal peptide, Y Score for general cleavage site.

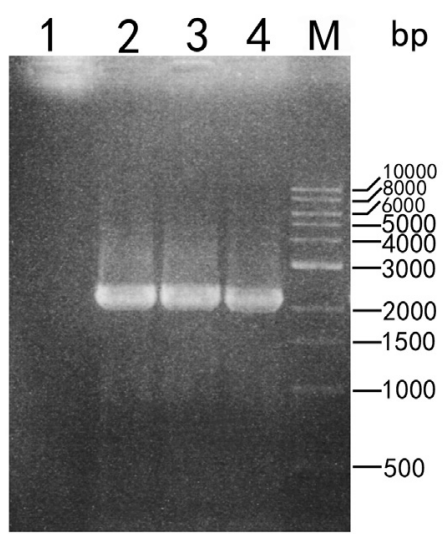

Figure 2. Gel electrophoresis of PCR products encoding the mature peptide-coding region of the AtSBT1.9 protein. Lane 1 = negative control without template in PCR; lanes 2-4 = PCR products of different clones; lane M = DNA marker. 


\section{Bacterial expression of AtSBT1.9 fusion protein}

The cDNA corresponding to the AtSBT1.9 mature peptide coding region was cloned into pMD18-T, and incorporated into expression vector pMAL-c2x. Digestion by BamHI and Sall was performed to screen for the recombinant pMAL-AtSBT1.9 (Figure 3).

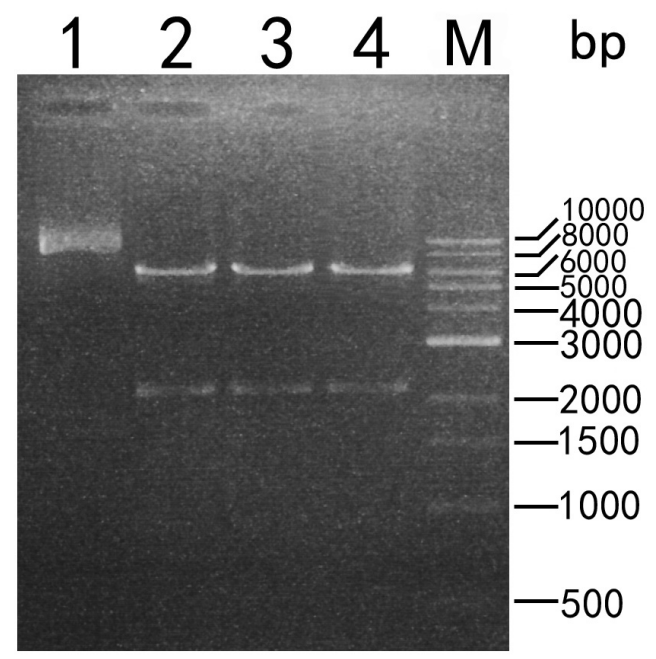

Figure 3. Double digestion with BamHI and Sall to verify presence of pMAL-AtSBT1.9. Lane 1 = negative control without restriction enzymes; lanes 2-4 = double digestion products; lane $M$ = DNA marker.

Upon IPTG induction, the E. coli BL21/pMAL-AtSBT1.9 expressed AtSBT1.9 fusion protein (Figure 4, lane 5). The fusion protein consists of a 40.0-kDa MBP tag (Figure 4, lane 3) and $77.5 \mathrm{kDa}$ of AtSBT1.9 mature peptide, designated as MBP-AtSBT1.9. Thus, the total size of the predicted fusion protein is $117.5 \mathrm{kDa}$. This roughly corresponds to the molecular size of the detected band of MBP-AtSBT1.9 on SDS-PAGE (Figure 4). The yield of the fusion protein could reach up to $11 \%(\mathrm{w} / \mathrm{w})$ of total BL21 proteins. Without IPTG induction, there was no detectable AtSBT1.9 fusion protein in the E. coli BL21/pMAL-AtSBT1.9 (Figure 4, lane 1), identical to what was produced by the PMAL-c2x vector (Figure 4, lane 2). Furthermore, the bacterial cell lysate was centrifuged to collect the supernatant and the pellet for SDS-PAGE analysis. The AtSBT1.9 fusion protein, as detected by SDS-PAGE, had been expressed in both the soluble phase and the insoluble form (i.e. as an inclusion body) (Figure 4, lanes 4 and 6).

A pair of parallel experiments with the same bacterial system but with IPTG induction at $18^{\circ}$ and $37^{\circ} \mathrm{C}$, were performed to test the effect of induction temperature on AtSBT1.9 fusion protein expression in E. coli. The difference in the amount of target protein between the liquid and pellet fractions was identified by western blotting analysis using an MBP antiserum (Figure 5). Although inclusion bodies were still observed when induced by IPTG at $18^{\circ} \mathrm{C}$, the amount of MBP-AtSBT1.9 protein in this case was much lower than that induced at $37^{\circ} \mathrm{C}$ (Figure 5). In contrast, induction at $18^{\circ} \mathrm{C}$ resulted in a significant increase in the amount of AtSBT1.9 fusion protein detected in the soluble phase, as compared with that at $37^{\circ} \mathrm{C}$ (Figure 5). Thus, the bacterial culture at $18^{\circ} \mathrm{C}$ was used for the production of the MBP-AtSBT1.9 protein. 


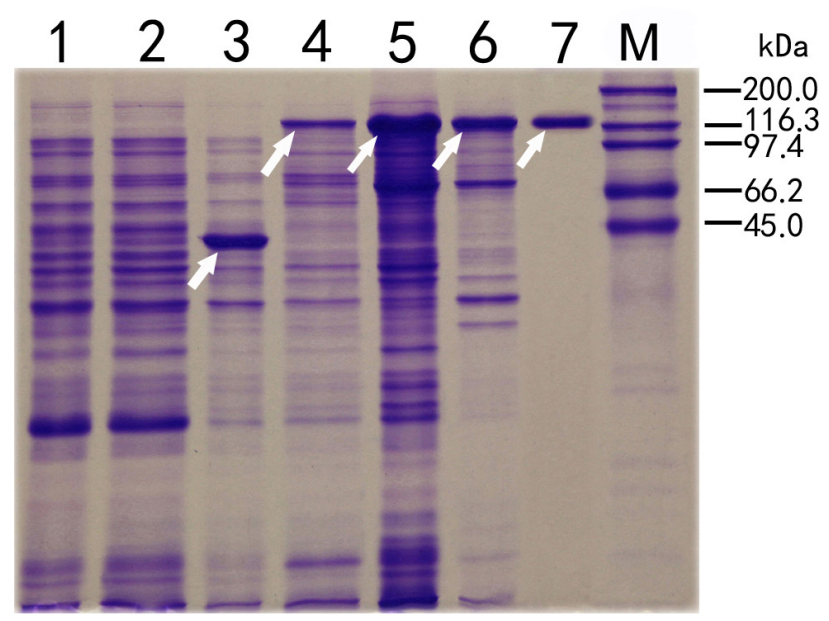

Figure 4. SDS-PAGE analysis of the expressed protein. Mature peptide of full-length AtSBT1.9 was expressed as an N-terminal MBP fusion protein, designated as MBP-AtSBT1.9. Lane 1 = uninduced BL21/pMAL-AtSBT1.9; lane 2 = uninduced BL21/pMAL-c2x; lane $3=$ induced BL21/pMAL-c2x; lane 4 = supernatant containing soluble fractions released from the induced BL21/pMAL-AtSBT1.9 after sonication; lane $5=$ induced BL21/pMAL-AtSBT1.9; lane $6=$ pellet containing insoluble fractions after sonication; lane 7 = purified MBP-AtSBT1.9; lane $M=$ molecular mass marker proteins. Arrows indicate MBP-AtSBT1.9 on lanes 4-7 and MBP protein on lane 3.

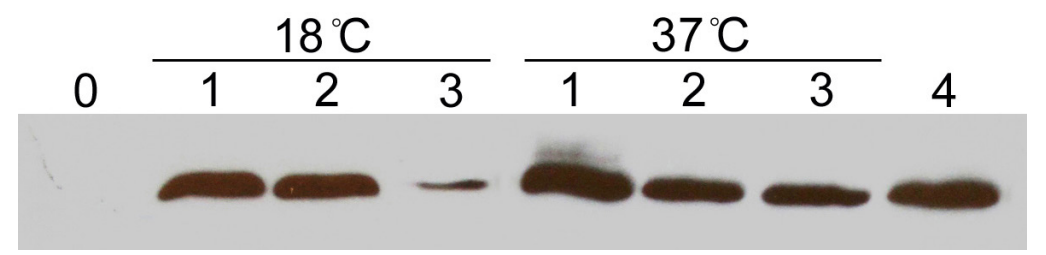

Figure 5. Induction temperature $\left(18^{\circ}\right.$ or $\left.37^{\circ} \mathrm{C}\right)$ affects the production of the MBP-AtSBT1.9 protein in E. coli BL21 (DE3) as detected by anti-MBP Western blotting. Lane $0=$ cell fraction of BL21/pMAL-AtSBT1.9, no IPTG induction; lane 1 = cell fraction of BL21/pMAL-AtSBT1.9, by IPTG induction; lane 2 = soluble lysates of BL21/pMAL-AtSBT1.9, by IPTG induction; lane $3=$ insoluble lysates of BL21/pMAL-AtSBT1.9, by IPTG induction; lane $4=$ the purified MBPAtSBT1.9 protein. For $100 \mu \mathrm{g}$ MBP-AtSBT1.9 induced at $18^{\circ} \mathrm{C}$, the amount of protein in the soluble and the insoluble lysates is 92 and $8 \mu \mathrm{g}$, respectively. Conversely, when induced at $37^{\circ} \mathrm{C}$, the amount of protein in soluble and insoluble lysates is 57 and $43 \mu \mathrm{g}$, respectively.

\section{Protease activity of AtSBT1.9 fusion protein}

After purification, the MBP-AtSBT1.9 protein (Figure 4, lane 7) showed a specific activity of $9.23 \mathrm{U} / \mathrm{mg}$ protein (Table 1). Totally, $87 \mathrm{mg}$ of AtSBT1.9 fusion proteins were obtained from $4 \mathrm{~L}$ of the original bacterial culture (Table 1). One of the parameters in our in vitro assay, either incubation temperature or $\mathrm{pH}$, was altered at a time, to identify its effects on protease activity. The effect of varying incubation temperature on activity was statistically significant in all assay protocols (Figure 6). As shown in Figure 6, activity increased up to $38 \%$ with an incubation temperature of $37^{\circ} \mathrm{C}$, whereas it decreased after a $42^{\circ} \mathrm{C}$ incubation, compared with that at $25^{\circ} \mathrm{C}$. A pH value range of 7-8 was detected as the optimal pH for activity (Figure 7). Activity at pH 2 and pH12 decreased by 96 and $83 \%$, respectively, compared with that at $\mathrm{pH} 7$ (Figure 7 ). 
Table 1. Yields and protease activity of the MBP-AtSBT1.9 fusion protein².

\begin{tabular}{lcccc}
\hline Purification step & Protein yield $(\mathrm{mg})$ & Recovery $(\%)$ & Total activity $(\mathrm{U})$ & Specific activity $(\mathrm{U} / \mathrm{mg})$ \\
\hline Cell lysates & $1042 \pm 17$ & 100 & $1229.56 \pm 8.12$ & $1.18 \pm 0.07$ \\
Purified protease & $87 \pm 2.3$ & 8.35 & $803.01 \pm 3.41$ & $9.23 \pm 0.12$ \\
\hline
\end{tabular}

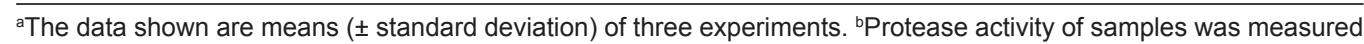
at $25^{\circ} \mathrm{C}, \mathrm{pH} 7$.

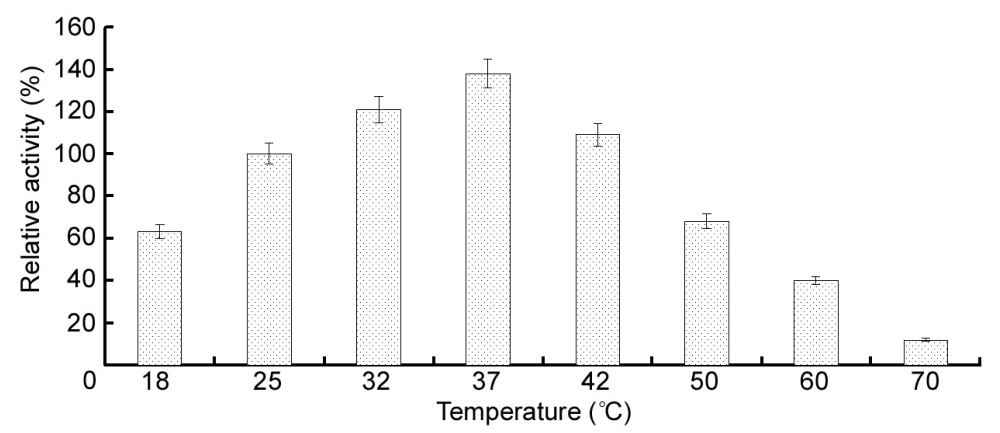

Figure 6. Incubation temperature affects protease activity of MBP-AtSBT1.9 protein in vitro assay at $\mathrm{pH}$ 7. The activity at $25^{\circ} \mathrm{C}$ was standardized as $100 \%$ (CK sample, corresponding to $9.23 \mathrm{U} / \mathrm{mg}$ protein), and other samples were then normalized against the $\mathrm{CK}$ for obtaining the relative activities. The data shown are means ( \pm standard deviation) of three experiments.

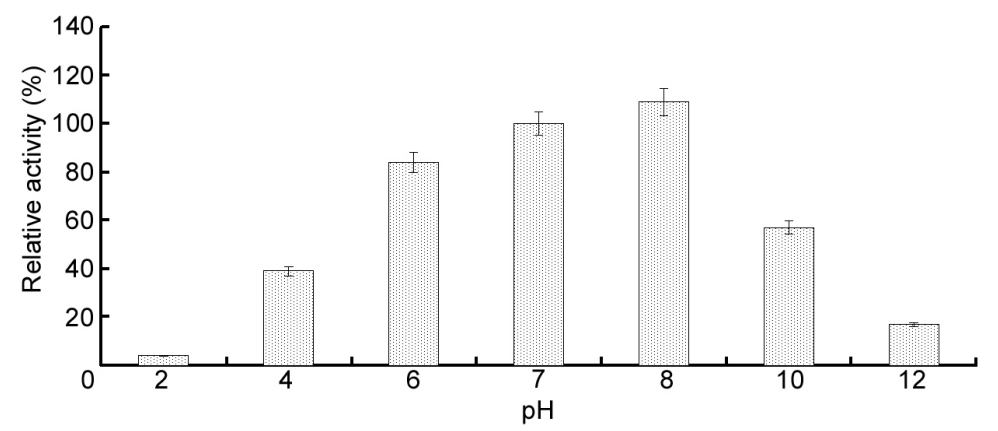

Figure 7. Incubation $\mathrm{pH}$ affects the protease activity of MBP-AtSBT1.9 protein in vitro assay at $25^{\circ} \mathrm{C}$. The activity at $\mathrm{pH} 7$ was standardized as $100 \%$ (CK sample, corresponding to $9.23 \mathrm{U} / \mathrm{mg}$ protein), and other samples were then normalized against the $\mathrm{CK}$ for obtaining the relative activities. The data shown are means ( \pm standard deviation) of three experiments.

To test whether the MBP tag in this fusion protein was responsible for the protease activity, AtSBT1.9 mature peptide after MBP elimination was measured for in vitro activity. As shown in Figure 8 , a similar activity was presented between the AtSBT1.9 mature peptide and the MBPtagged one. To test how, if the signal peptide was not cleaved, the activity might be altered compared to properly processed AtSBT1.9 mature peptide, the full-length AtSBT1.9 containing its signal peptide and mature peptide was also fused to the MBP tag. In this case, both the expressed proteins, with and without MBP, showed no protease activity under the same assay conditions (Figure 8). 


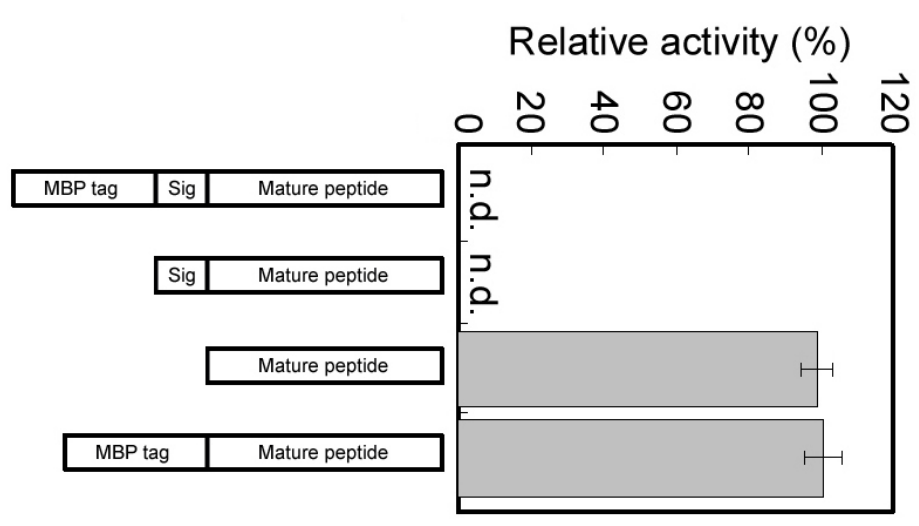

Figure 8. Protease activities of the expressed AtSBT1.9 proteins with different fusion forms. Schematic diagrams of the constructs used for in vitro assays are shown at left. Protease activity was monitored at $25^{\circ} \mathrm{C}, \mathrm{pH}$. The activity of MBP-tagged mature peptide of AtSBT1.9 was standardized as 100\% (CK sample, corresponding to 9.23 $\mathrm{U} / \mathrm{mg}$ protein), and other samples were then normalized against the CK for obtaining the relative activities. The data shown are means ( \pm standard deviation) of three experiments. MBP tag, maltose-binding protein; Sig, AtSBT1.9 signal peptide; mature peptide, AtSBT1.9 mature peptide; n.d., not detectable.

\section{DISCUSSION}

We cloned an A. thaliana subtilase AtSBT1.9 gene, then demonstrated that this subtilase could effectively be produced as a fusion protein (MBP-AtSBT1.9) in E. coli, and that it possessed protease activity in vitro. The majority of known subtilases contain a signal peptide domain that targets the protein for extracellular secretion, and a mature peptide domain that exhibits degradative activity (Rautengarten et al., 2005). Processing at N-terminus of the protein appears to be a common feature of $A$. thaliana subtilases (Rautengarten et al., 2005; Sénéchal et al., 2014). The AtSBT1.9 gene is predicted to encode an N-terminus signal peptide of 20 amino acids. It is interesting that the expressed full-length AtSBT1.9 protein, including its signal peptide in E. coli showed no protease activities. These data indicated that the $E$. coli expression system could not recognize the endogenous signal peptide of AtSBT1.9, which resulted in no activation peptides. Therefore, a partial AtSBT1.9 cDNA, corresponding to its mature peptide, was expressed in $E$. coli. The AtSBT1.9 protein was expressed using a prokaryotic system for a number of reasons. Compared with other expression systems, E. coli serves as an excellent host for recombinant protein production because it provides an economical and fast way to produce the molecules in relatively large amounts, although yields of correctly folded and functional protein can be low because of protein aggregation ( $\mathrm{Li}$ and $\mathrm{Li}, 2009$ ). However, the pMAL protein fusion system provides a convenient method for directing fusion proteins to the periplasm where they are allowed to fold. Although expressed MBP-AtSBT1.9 was observed in both the soluble phase and in the form of inclusion bodies, with a nearly equal yield of each at $37^{\circ} \mathrm{C}$ induction, an optimal induction temperature of $18^{\circ} \mathrm{C}$ resulted in a significantly increased yield of fusion protein in the soluble phase. Moreover, because of the availability of a commercial anti-MBP antibody, it is convenient to detect MBP-tagged proteins with good sensitivity using western blotting.

Subtilases are characterized by a catalytic triad of the three amino acids: aspartate, histidine, and serine (Dodson and Wlodawer, 1998). Subtilases catalyze many fundamental proteolytic reactions involved in a wide variety of essential processes, including development, 
physiology, and adaptation to changing environments (Figueiredo et al., 2014). There are fiftysix subtilase genes (the AtSBT genes) in A. thaliana genome (Rautengarten et al., 2005). These subtilasescan be subdivided into six distinct subtilase subfamilies based on amino acid sequence similarity (Rautengarten et al., 2005). Nine members (AtSBT1.1 to AtSBT1.9) are included in the subfamily I. Of the nine subfamily I members, only the function of AtSBT1.2 has been investigated. AtSBT1.2 is involved in development of stomatal density and distribution, possibly through generation of peptide signals (von Groll et al., 2002). Although AtSBT1.9 function is currently unknown, we expect that the AtSBT1.9 gene should be functional in $A$. thaliana, because the sequence conservation within the subfamily I, according to the subtilase phylogeny constructed by Rautengarten et al. (2005), reflects some conservation of enzyme function. Moreover, ubiquitous expression of the AtSBT1.9 gene is indicative of an essential function. However, AtSBT1.9 activity screening is complicated because of the low abundance of the protein in its natural form, and the difficulty involved in purifying it due to its instability. Heterologous expression of the target protein provides an alternative strategy for functional characterization. Here, we expressed an AtSBT1.9 fusion protein in bacteria, which provides a relatively economical method for assessing its activity and biochemical characterization, versus the complexity of purifying the protein from the $A$. thaliana plant. Furthermore, the AtSBT1.9 fusion protein was shown to be a bioactive subtilase. The natural AtSBT1.9, thus, seems likely to contribute to the proteolysis involved in multiple physiological pathways in $A$. thaliana.

In conclusion, protease activity of AtSBT1.9was validated by the expression of its cDNA in $E$. coli for the in vitro assay. The recombinant AtSBT1.9 showed maximal activity over broad $\mathrm{pH}$ $(7-8)$ and temperature $\left(25^{\circ}-42^{\circ} \mathrm{C}\right)$ optima, which has not been reported to date from $A$. thaliana. These findings suggest that the AtSBT1.9 protein potentially has proteolytic functions involved in $A$. thaliana physiological processes. Moreover, a possible practical application of the AtSBT1.9 fusion proteinneed to be used as a probe to screen putative protein-protein interactions involved in signal pathway networks in $A$. thalianaby co-immunoprecipitation and/or pull-down approaches.

\section{Conflicts of interest}

The authors declare no conflict of interest.

\section{ACKNOWLEDGMENTS}

Research supported by the grants from the National Natural Science Foundation of China (\#31171944 and \#30771483), the Key Subject Construction of Biology in Anhui Province, China (\#2014SKQJ021), the Anhui Agricultural University for the Subject-Talents Program (\#2014XKPY-43), and the Scientific Research Foundation for the Returned Overseas Chinese Scholars, State Education Ministry, China (\#2015-1098).

\section{REFERENCES}

Cheng G, Zhao P, Tang XF and Tang B (2009). Identification and characterization of a novel spore-associated subtilase from Thermoactinomyces sp. CDF. Microbiology 155: 3661-3672.

Dodson G and Wlodawer A (1998). Catalytic triads and their relatives. Trends Biochem. Sci. 23: 347-352.

Figueiredo A, Monteiro F and Sebastiana M (2014). Subtilisin-like proteases in plant-pathogen recognition and immune priming: a perspective. Front. Plant Sci. 5: 739. 
Li DH and Li JZ (2009). Antifungal activity of a recombinant defensin CADEF1 produced by Escherichia coli. World J. Microbiol. Biotechnol. 25: 1911-1918.

Liu JX, Srivastava R and Howell S (2009). Overexpression of an Arabidopsis gene encoding a subtilase (AtSBT5.4) produces a clavata-like phenotype. Planta 230: 687-697.

Meichtry J, Amrhein $\mathrm{N}$ and Schaller A (1999). Characterization of the subtilase gene family in tomato (Lycopersicon esculentum Mill.). Plant Mol. Biol. 39: 749-760.

Matos JL, Fiori CS, Silva-Filho MC and Moura DS (2008). Aconserved dibasic site is essential for correct processing of the peptide hormone AtRALF1 in Arabidopsis thaliana. FEBS Lett. 582: 3343-3347.

Ramírez V, López A, Mauch-Mani B, Gil MJ, et al. (2013). An extracellular subtilase switch for immune priming in Arabidopsis. PLoS Pathog. 9: e1003445.

Rautengarten C, Steinhauser D, Büssis D, Stintzi A, et al. (2005). Inferring hypotheses on functional relationships of genes: analysis of the Arabidopsis thaliana subtilase gene family. PLoS Comput. Biol. 1: e40.

Rautengarten C, Usadel B, Neumetzler L, Hartmann J, et al. (2008). A subtilisin-like serine protease essential for mucilage release from Arabidopsis seed coats. Plant J. 54: 466-480.

Sénéchal F, Graff L, Surcouf O, Marcelo P, et al. (2014). Arabidopsis PECTIN METHYLESTERASE17 is co-expressed with and processed by SBT3.5, a subtilisin-like serine protease. Ann. Bot. 114: 1161-1175.

Tripathi LP and Sowdhamini R (2006). Cross genome comparisons of serine proteases in Arabidopsis and rice. BMC Genomics 7: 200.

von Groll U, Berger D and Altmann T (2002). The subtilisin-like serine protease SDD1 mediates cell-to-cell signaling during Arabidopsis stomatal development. Plant Cell 14: 1527-1539. 